\title{
Data from experiments on bubbling fluidization of group B glass particles
}

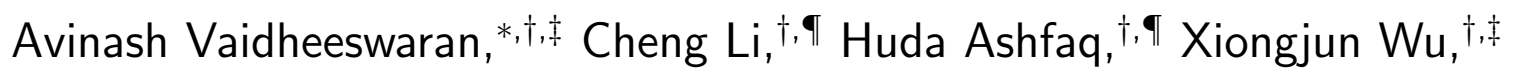 \\ Steven Rowan, ${ }^{\dagger, \ddagger}$ and William A. Rogers ${ }^{\dagger}$ \\ $\dagger$ National Energy Technology Laboratory, Morgantown, WV \\ $\ddagger L R S T$, Morgantown, WV \\ ฯ Oak Ridge Institute of Science and Education, Oak Ridge, TN \\ E-mail: avinash.vaidheeswaran@netl.doe.gov
}

\begin{abstract}
Experiments on bubbling fluidization were performed in three cylindrical columns having internal diameters of 2.5, 4 and 6 inches. Though not scaled hydrodynamically, the systems are designed to have considerably high particle count compared to majority of controlled experiments reported in the literature. A systematic testing procedure was followed involving replicates and randomization to estimate uncertainty and avoid unintended bias. Glass particles having a sauter mean diameter of $332 \mu \mathrm{m}$ were used and the superficial velocity of air at the inlet was varied from 2.97 - 5.35 times minimum fluidization velocity. Mean and standard deviation of differential pressure and interface height are the quantities of interest reported in this work. The results obtained from these experiments are found to be consistent with the previous studies. Besides elucidating the underlying physics, such datasets are critical to assess predictive capability of coarse-grained modeling techniques like Particle-In-Cell (PIC) or Coarse-Grained Discrete Element Model (DEM) developed for large-scale applications .
\end{abstract}




\section{Introduction}

Fluidization has been widely used in the field of chemical engineering due to favorable mixing and heat and mass transfer characteristics ${ }^{1-6}$. Several researchers including Glicksman ${ }^{7}$, Horio et al. ${ }^{8}$, van den Bleek and Schouten ${ }^{9}$, Schouten et al. ${ }^{10}$, Briongos and Guardiola ${ }^{11}$ have analyzed this process to aid in design and scale-up of efficient reactors. For instance Glicksman ${ }^{7}$ proposed several non-dimensional groups to be considered while scaling including $\frac{g d_{p}}{u_{0}^{2}}, \frac{\rho_{s}^{2} d_{p}^{3} g}{\mu_{g}^{2}}, \frac{\rho_{g}}{\rho_{s}}, \frac{L}{d_{p}}, \frac{D}{d_{p}}$ which represent Froude number, modified Archimedes number, density ratio, ratio of bed height to particle diameter, and ratio of bed diameter to particle diameter respectively. Albeit, it might not be possible to consider all the non-dimensional groups at once to scale a system from laboratory-scale to pilot-scale or industry-scale. This would require changing the properties of material as well as fluidizing medium which might not be practical $^{12}$.

It is more feasible to scale the geometry while the properties of material and fluidizing medium are held constant. ${ }^{8,13-17}$ Even though this approach might not be consistent with a true scale-up effort, these experiments are essential to enhance our understanding of multi-phase dynamics at different scales. This is vital from a Simulation Based Engineering (SBE) point of view, which aims at predicting the behavior at different scales using highquality experimental data or results from numerical simulations having a high resolution. The work presented contributes to the existing repository of experimental datasets related to the Quality Assurance program of the Multiphase Flow Science group at National Energy Technology Laboratory which develops and maintains the open-source software MFiX (Multiphase Flow with Interphase Exchanges). Over the past few years, there has been an increasing emphasis on Verification, Validation and Uncertainty Quantification applied to granular and multiphase flows ${ }^{18-20}$. This is made possible by active collaboration between experimental and computational groups as envisioned by the ASME V\&V (Verification and Validation) guidelines ${ }^{21}$.

Experiments have been designed in the current study to obtain objectively assessed 
data which could be used for validating coarse-grained techniques such as Particle-In-Cell (PIC) or Coarse-Grained Discrete Element Model (DEM). Computations using conventional Langrangian-based strategies, for example DEM, pose a limitation while modeling industrialscale systems where particle counts become intractable. On the other hand, Eulerian TwoFluid Model (TFM) is prone to inaccuracies while modeling static or near-static regions where the motion of solids is mainly governed by inter-particle friction ${ }^{20,22}$. Also, adding multiple components to a TFM framework introduces greater uncertainty in constitutive relations ${ }^{23}$. Coarse-grained techniques have thus been increasingly favored, however highquality data for benchmarking such methodologies are very scarce in literature.

In this analysis, three geometries having internal diameters of 2.5 inch, 4 inch and 6 inch were considered. Glass beads having a Sauter mean diameter of $332 \mu \mathrm{m}$ were used in these experiments. Flow velocity of air at inlet was varied from 2.97-5.35 times the minimum fluidization velocity, while the range of particle Reynolds number and density ratio were held constant across the experiments. Measurements of differential pressure in different regions and interface height are reported. Results obtained from this systematic study provide a valuable database for a rigorous validation and uncertainty quantification of computational models and constitutive relations besides aiding in understanding the hydrodynamics at different scales.

\section{Experimental Setup and Procedure}

\section{Preliminaries}

Glass particles used in this study were characterized using QICPIC (manufactured by Sympatec $\mathrm{GmBH}$ ). Distribution density of particle diameter is shown in Figure 1. These particles have a sauter mean diameter of $332 \mu \mathrm{m}$ and are classified under Group B ${ }^{24}$ characterized by good mixing behavior and vigorous bubbling ${ }^{2}$. Figure 2 shows the cumulative distribution of

sphericity and aspect ratio, having a median value of 0.93 and 0.97 respectively. In addition, 
Figure 1 also shows an example of distribution density from the 4-inch cylindrical column after fluidization experiments thereby confirming negligible effects due to fragmentation or attrition. It is important to identify changes in size distribution to make the validation study more consistent.

Following particle characterization, tests were performed to estimate minimum fluidization velocity, $U_{m f}$ in all the columns. Further details regarding the procedure can be found in Vaidheeswaran at al. ${ }^{25}$. Table 1 summarizes values obtained in the 2.5-inch, 4-inch and 6 -inch units which are consistent with previous findings of Cranfield and Geldart ${ }^{26}$, Eisfeld and Schnitzlein ${ }^{27}$, Delbarre ${ }^{28}$, Di Felice and Gibilaro ${ }^{29}$ and Rao et al. ${ }^{30}$. Furthermore, Rao et al. ${ }^{30}$ suggest that the friction effects due to wall increases as the hydraulic diameter is reduced which leads to an increase in $U_{m f}$ for smaller geometries. Hence, a greater gas-phase inertia is required to support the weight of bed material and overcome resistance due to wall. Table 1: Minimum fluidization velocity measurements from test sections used in the current study

\begin{tabular}{cc}
\hline Internal diameter (inch) & $U_{m f}(\mathrm{~m} / \mathrm{s})$ \\
\hline 2.5 & 0.079 \\
4.0 & 0.073 \\
6.0 & 0.070 \\
\hline
\end{tabular}

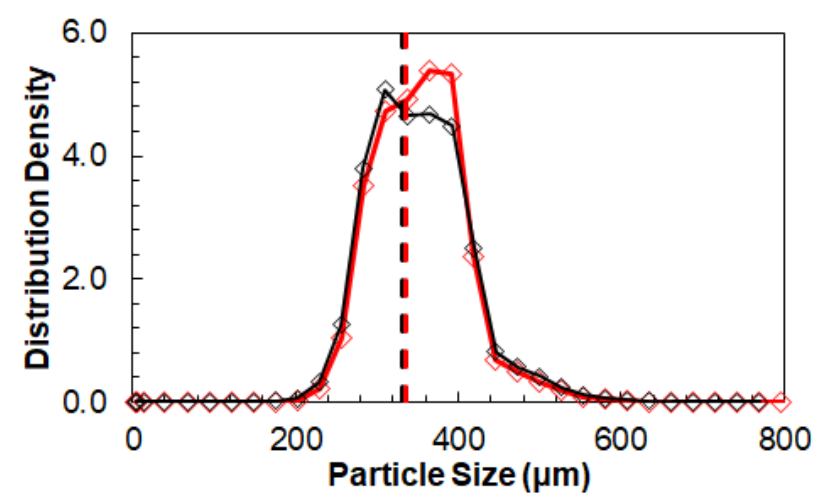

Figure 1: Distribution density of particle size before (black) and after (red) the experiments in 4-inch column. Dashed lines represent the respective Sauter Mean Diameter. 

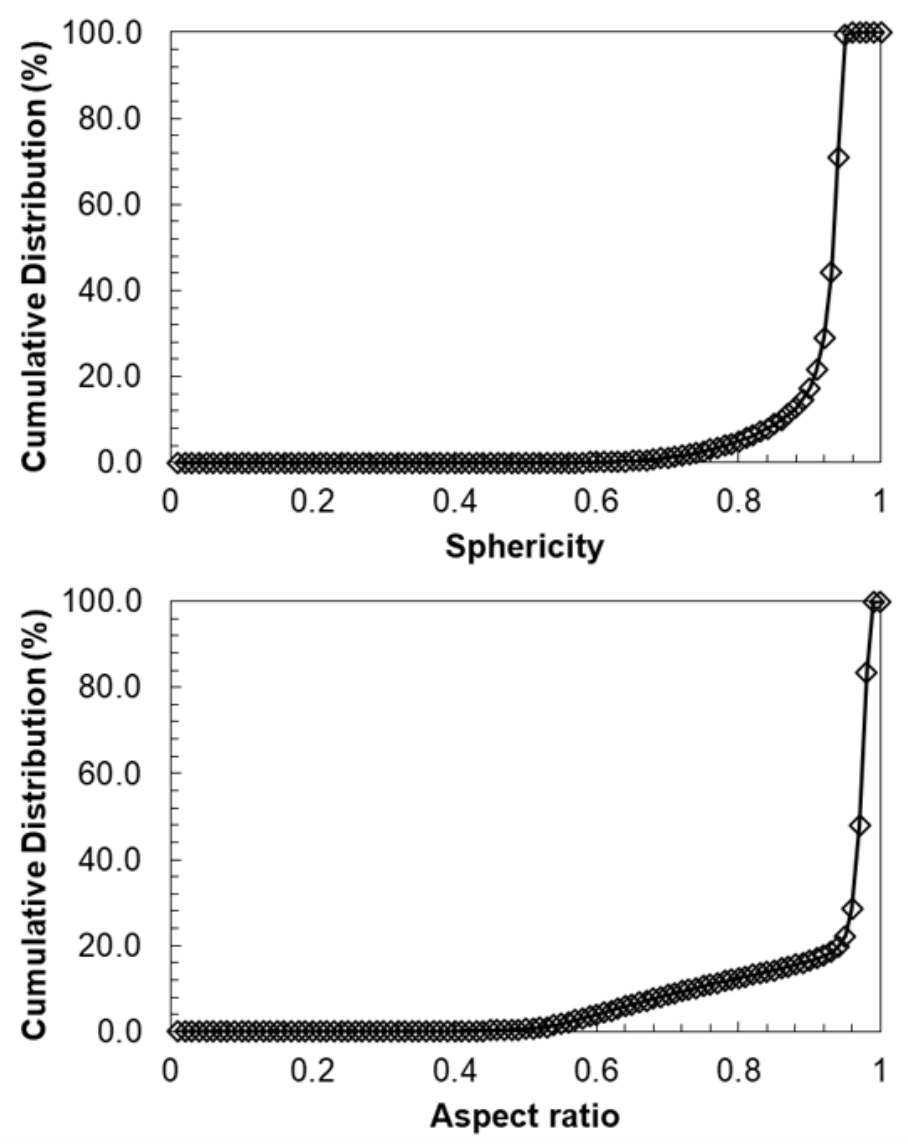

Figure 2: Cumulative distribution of sphericity (top) and aspect ratio (bottom) from a sample of glass particles used in the current study. 


\section{Fluidization Experiments}

Fluidization experiments were performed in cylindrical test sections having internal diameters 2.5-inch, 4-inch and 6-inch as depicted in Figure 3. The following differential pressure measurements are reported in the current study: $\Delta P_{2}=P_{1}-P_{2}, \Delta P_{3}=P_{2}-P_{3}$, $\Delta P_{4}=P_{3}-P_{6}$ and $\Delta P_{5}=P_{1}-P_{6}$ for the 2.5-inch test section and $\Delta P_{2}=P_{1}-P_{3}$, $\Delta P_{3}=P_{3}-P_{4}$ and $\Delta P_{6}=P_{1}-P_{5}$ for the 4-inch and 6-inch units. The exact location of pressure ports are summarized in Table 2. Differential pressure signals were recorded at $100 \mathrm{hz}$ for a duration of 180 seconds. High-Efficiency Particulate Air (HEPA) filters were used at the exit to trap particles being elutriated from the units. Tests were performed in a randomized order which includes replicates as shown in Table 3. $U / U_{m f}$ values were based on the minimum fluidization velocity measured in the 2.5 -inch test section. Distributor plates consisting of sintered porous metal filter (Mott Corp, Grade 40) was used at the inlet to provide uniform flow conditions. The test sections were filled with glass beads up to about 6 inches from the distributor plate. Mass of particles loaded in the 2.5-inch, 4-inch and 6-inch test sections was $785.7 \mathrm{~g}, 1902.6 \mathrm{~g}$ and $3801.7 \mathrm{~g}$ which correspond to particle counts of the order of $8 \times 10^{6}, 20 \times 10^{6}$ and $40 \times 10^{6}$. Leak tests were performed before and after the experiments and leaks were not detected in the test sections.

Besides pressure signals, bed height statistics were measured for one setting of each flow condition in all the columns. A high-speed Phantom v341 Complementary Metal Oxide Semiconductor (CMOS) camera was used for visualization, and the instantaneous location of the interface was extracted by image processing. The units were back lit by a Light Emitting Diode (LED) source and the light is diffused by translucent paper. High-speed videos were recorded at $100 \mathrm{hz}$ for 60 seconds once the pressure signals were stationary in a statistical sense. The series of images were first cropped to include only the transparent portion of the bed followed by thresholding using the method of Otsu ${ }^{31}$. Instantaneous interface locations were then extracted from the resulting black and white images. 


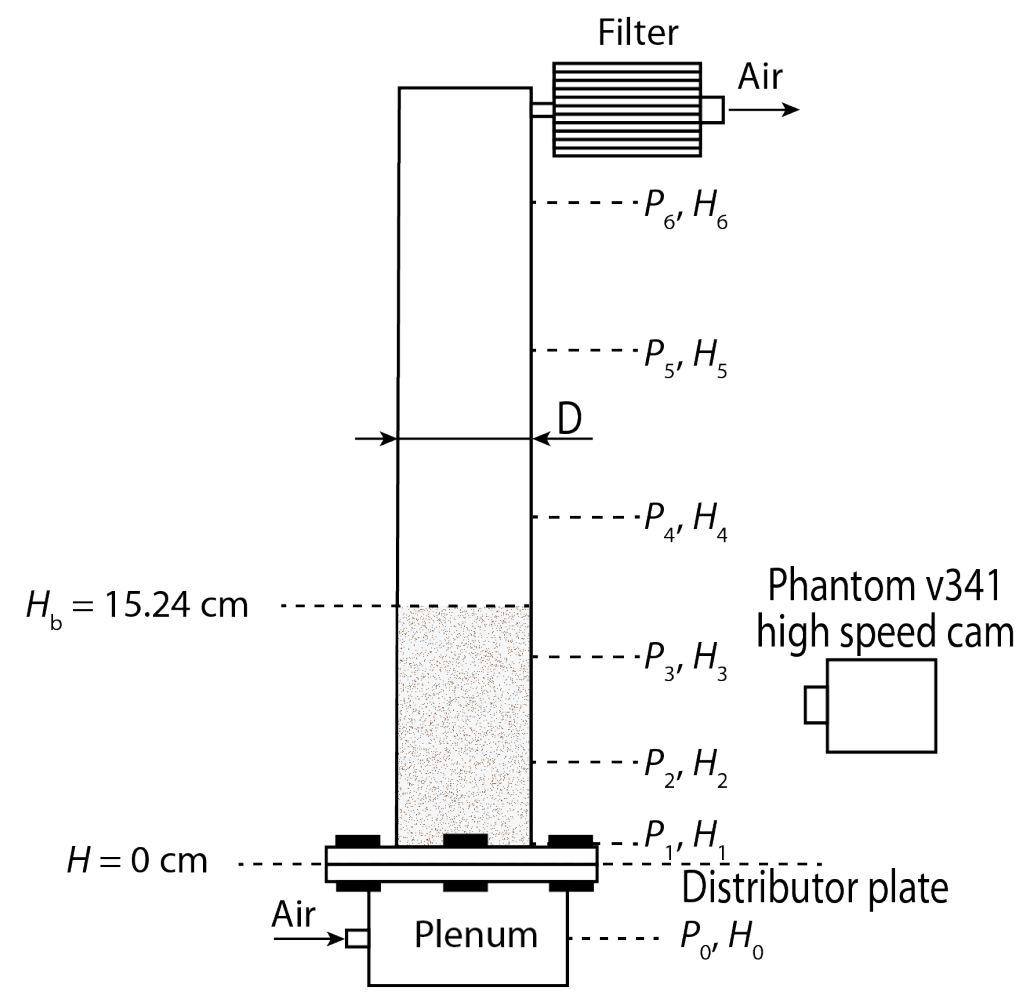

Figure 3: Schematic showing cylindrical columns used in the current study: (a) 2.5-inch, (b) 4-inch (c) 6-inch.

Table 2: Location of pressure ports in 2.5-inch, 4-inch and 6-inch units.

\begin{tabular}{ccccccccc}
\hline Unit & $D(\mathrm{~cm})$ & $H_{0}(\mathrm{~cm})$ & $H_{1}(\mathrm{~cm})$ & $H_{2}(\mathrm{~cm})$ & $H_{3}(\mathrm{~cm})$ & $H_{4}(\mathrm{~cm})$ & $H_{5}(\mathrm{~cm})$ & $H_{6}(\mathrm{~cm})$ \\
\hline 2.5-inch & 6.35 & -14.61 & 0.56 & 6.03 & 11.11 & - & - & 86.26 \\
4.0-inch & 10.16 & -19.00 & 3.60 & - & 11.10 & 18.60 & 26.10 & 95.07 \\
6.0-inch & 15.24 & -43.46 & 6.25 & - & 11.43 & 19.05 & 26.67 & 150.16 \\
\hline
\end{tabular}

Table 3: Test procedure showing the order of experiments and the corresponding $U / U_{m f}$. $U_{m f}=0.079 \mathrm{~m} / \mathrm{s}$ measured in the 2.5 -inch column is used as reference value.

\begin{tabular}{cc|cc|cc}
\hline Order & $U / U_{m f}$ & Order & $U / U_{m f}$ & Order & $U / U_{m f}$ \\
\hline 1 & 2.97 & 11 & 3.57 & 21 & 2.97 \\
2 & 4.16 & 12 & 3.57 & 22 & 4.76 \\
3 & 3.57 & 13 & 5.35 & 23 & 4.16 \\
4 & 5.35 & 14 & 4.76 & 24 & 4.76 \\
5 & 3.57 & 15 & 5.35 & 25 & 4.16 \\
6 & 4.16 & 16 & 4.76 & 26 & 3.57 \\
7 & 4.16 & 17 & 2.97 & 27 & 4.76 \\
8 & 5.35 & 18 & 5.35 & 28 & 2.97 \\
9 & 4.76 & 19 & 3.57 & 29 & 2.97 \\
10 & 4.16 & 20 & 2.97 & 30 & 5.35 \\
\hline
\end{tabular}




\section{Results}

\section{Pressure Statistics}

Experiments were performed in the order listed in Table 3 in all three columns. Statistics of differential pressure across regions having significant mass of glass particles are reported. Figure 4 shows mean and standard deviation of differential pressure measurements in the 2.5-inch test section. The values are reported based on mean from replicates for each $U / U_{m f}$. Error bars represent 95\% confidence interval calculated using t-statistic. Mean values seen in Figure 4 (top) remain fairly constant across the range of $U / U_{m f}$ being considered. There is a slight drop in $\overline{\Delta P_{3}}$ compared to $\overline{\Delta P_{2}}$ while $\overline{\Delta P_{4}}$ is greater. Mean differential pressure is indicative of solids hold-up in the region across which it is measured. There is a greater concentration of solids in the region corresponding to $\Delta P_{4}$ compared to $\Delta P_{2}$ and $\Delta P_{3}$. $\overline{\Delta P_{5}}$ represents the mean weight of bed material excluding solids in the region between the distributor plate and the first port above it (refer Figure 3). On the other hand, standard deviation values increase with increase in flow rate as seen in Figure 4 (bottom). This is observed across all regions and the results are consistent with the previous findings of Bi et al. ${ }^{32}$, Schnitzlein and Weinstein ${ }^{33}$, Grace and Sun $^{34}$ and Sobrino et al. ${ }^{35}$. The mean values recorded in the 4-inch and 6-inch test sections follow a similar trend as seen in Figures 5 \& 6. There is negligible change over the range of $U / U_{m f}$ except for $\overline{\Delta P_{3}}$ in the 4-inch test

section where a slight reduction is noticed. $\overline{\Delta P_{3}}$ and $\sigma_{\Delta P_{3}}$ are greater than $\overline{\Delta P_{2}}$ and $\sigma_{\Delta P_{2}}$ in the 4-inch column while they are lesser in the 6-inch column. Also, $\sigma_{\Delta P_{2}}$ and $\sigma_{\Delta P_{6}}$ measured in 4-inch and 6-inch columns are nearly identical (within measurement uncertainty), where $\Delta P_{6}$ in these units represents solids in the bed barring the region between distributor plate and the first port above it. It is worth emphasizing that mean and standard deviation of differential pressure are strongly dependent on the location of probes besides operating conditions.

According to $\mathrm{Bi}^{36}$ fluctuations in pressure signal arise from multiple sources including: 
(i) forming, coalescence and breaking of bubbles, (ii) bubble eruption at the interface, (iii) passage of bubbles (iv) interactions between fluidized particles and (v) gas-phase oscillations in plenum chamber. Pressure fluctuations due to gas-phase turbulence in plenum occur for distributors of low resistance while those due to particle interactions are dominant very close to the distributor plate ${ }^{36}$. In the current study, we may conclude that most of the oscillations arise due to factors (i), (ii) and (iii) listed above. Furthermore, pressure signals tend to get modulated depending on the dynamics in the fluidizing medium. They get amplified by selfexcited particle oscillations when the bed is sufficiently fluidized or attenuated due to excess energy dissipation. It is hence difficult to characterize the interactions between fluctuations from different sources and associate them with the statistics of differential pressure.
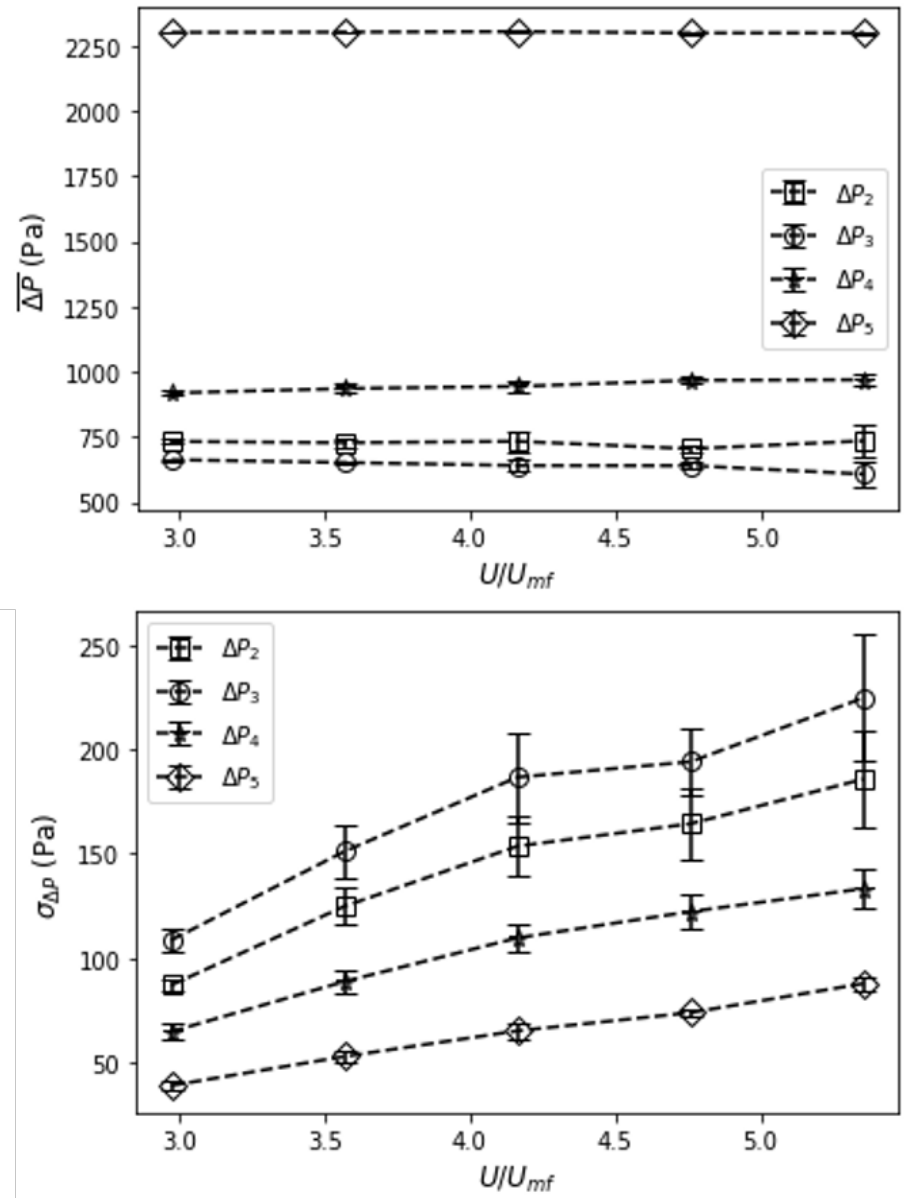

Figure 4: Mean (top) and Standard deviation (bottom) of differential pressure in 2.5-inch column. 

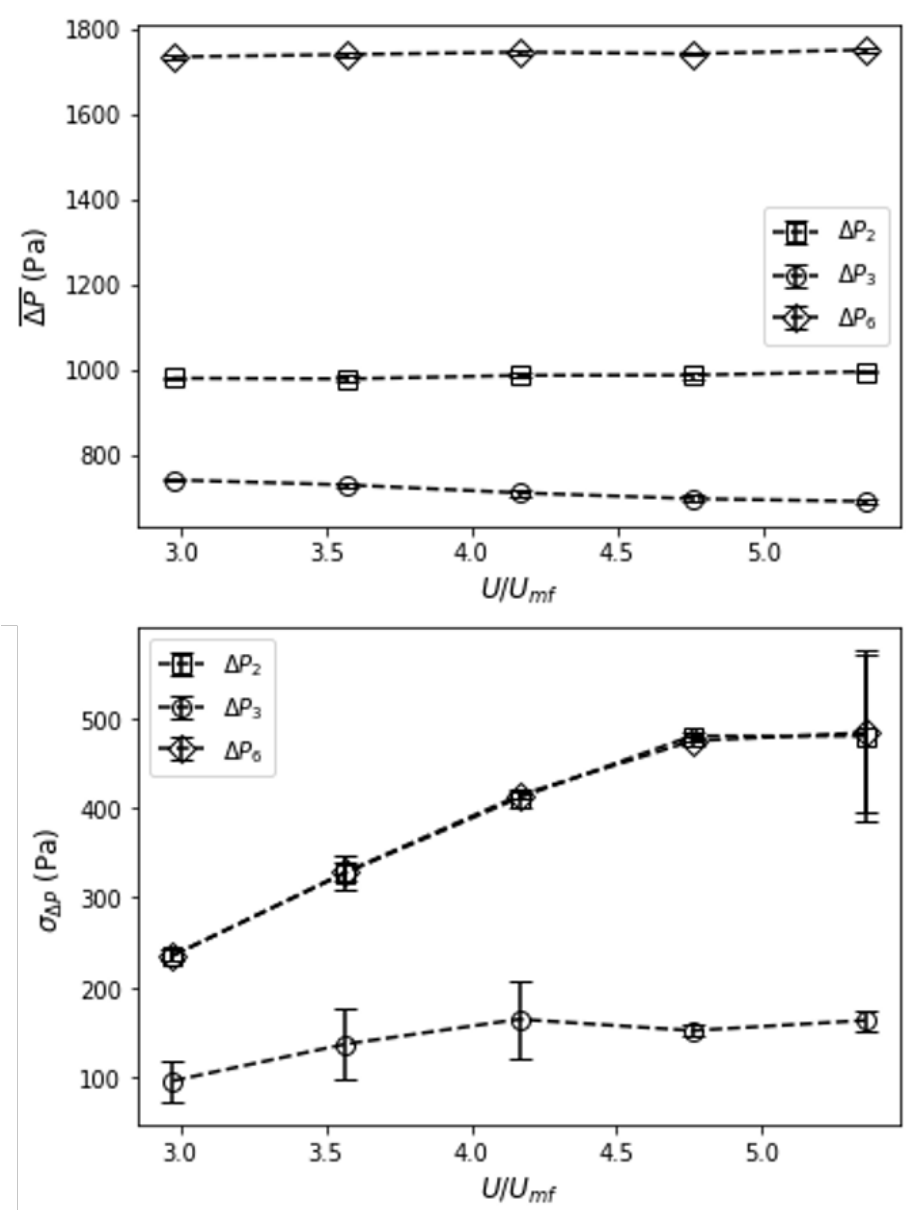

Figure 5: Mean (top) and Standard deviation (bottom) of differential pressure in 4-inch column. 

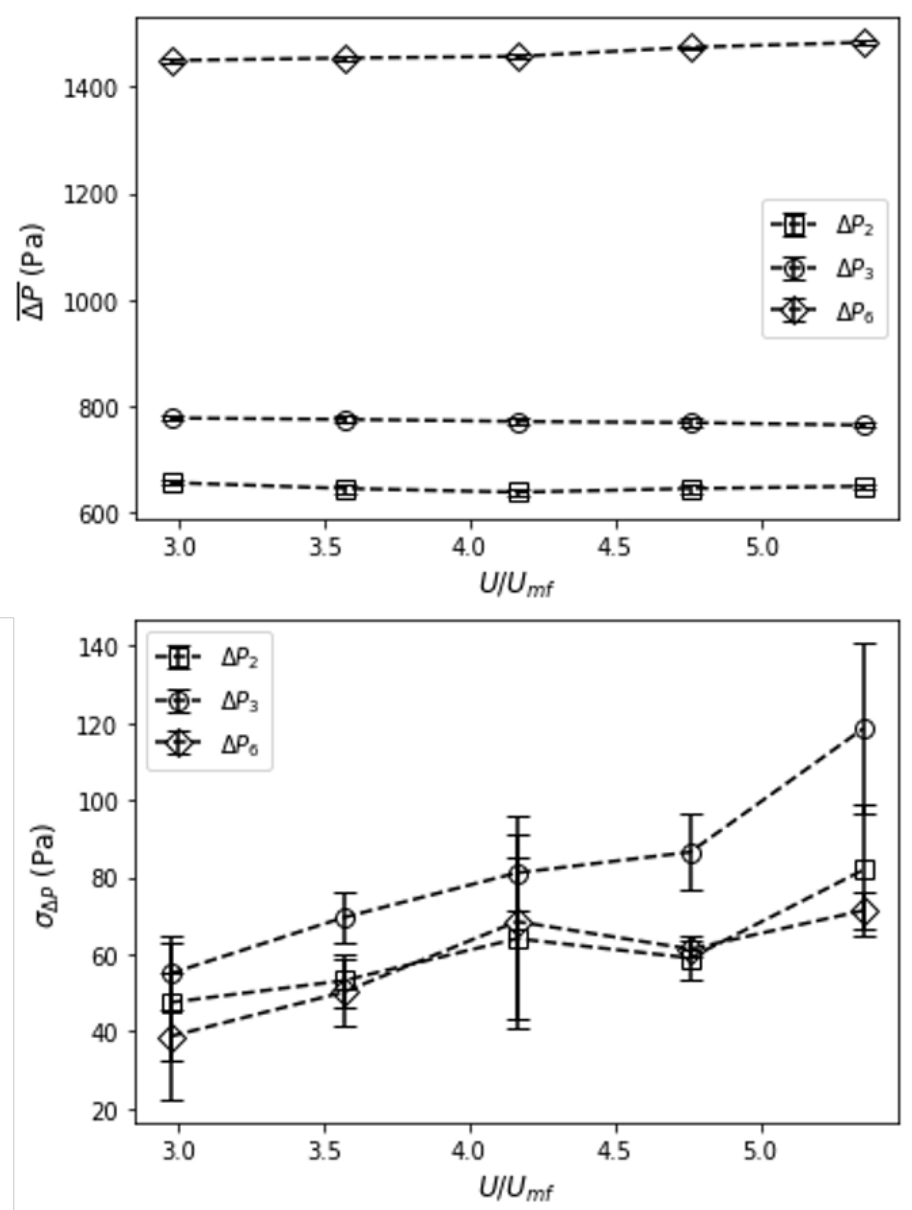

Figure 6: Mean (top) and Standard deviation (bottom) of differential pressure in 6-inch column. 


\section{Bed Height Statistics}

Bed height or interface location is the second quantity of interest considered in this study. It represents the boundary between dense bed and freeboard regions. Bubbles being formed closer to the distributor plate propagate upward and erupt once they reach the interface. This ejects particles on to the freeboard region. In this study, the units are operated in bubbling fluidization regime and hence elutriation of particles is minimized significantly if not eliminated. Figure 7 shows instantaneous snapshot from the 4-inch unit at different flow rates. Red lines represent heights determined using the procedure outlined previously where the threshold value is set to $10 \%$. The resulting time series data are used to derive bed height statistics plotted in Figures 8, 9 and 10. Abscissa in these plots correspond to threshold value or fraction of pixels occupied by particle-phase, which has been used to avoid a subjective definition of interface. As the superficial velocity of gas is increased, bed expands which causes the average height of interface to increase monotonically in all the units. The mean values drop with increase in threshold as expected. At higher fluidization velocities, excess air velocity $U-U_{m f}$ is higher which increases the size of bubbles. As a result, interface oscillations are more vigorous leading to an increase in the standard deviation of bed height. Their values are almost independent of threshold in the 2.5-inch unit, while they reduce with increase in threshold in the 4-inch and 6-inch units. The findings are consistent with other interface height measurements in literature including Geldart ${ }^{37}$, Guardiola et al. ${ }^{38}$ and Penn et al. ${ }^{39}$.

\section{Conclusions}

The effect of varying $U / U_{m f}$ on bubbling fluidization was investigated using detailed measurements from controlled experiments having well-characterized operating conditions. Mean and standard deviation of the quantities of interest are provided with uncertainty estimates in the form of confidence intervals for differential pressure and threshold dependence for 


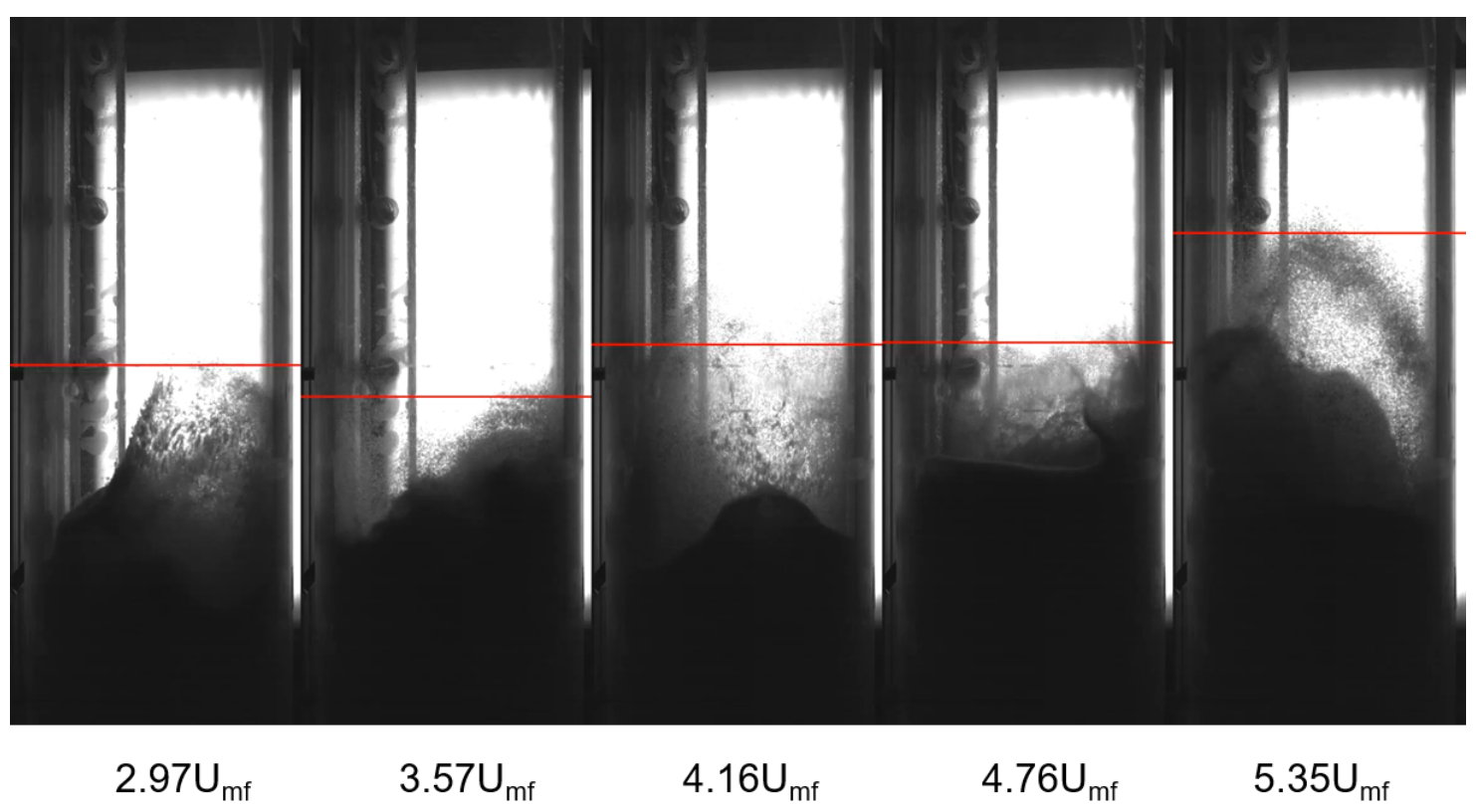

Figure 7: Instantaneous snapshots from the 4-inch unit at different flow rates. Red lines correspond to interface location determined using a 10\% threshold.

interface height. Superficial velocity of air at inlet (in the range considered) had negligible effect on the mean of differential pressure across all regions, while standard deviation was found to increase with increase in $U / U_{m f}$. Mean of interface height increased with increase in $U / U_{m f}$ resulting from enhanced bed expansion, while standard deviation increased due to formation of larger bubbles and their eruption at the interface. Caution must be exercised while drawing further conclusions from these measurements since the operating units were not scaled hydrodynamically. The study provides reliable high-quality data for validating computational models where systems have considerably high particle count, which are scarce in open literature. Similar efforts are needed to assess the credibility of modeling approaches such as PIC or Coarse-Grained DEM applicable for industrial-scale systems and improve their prediction capability. 

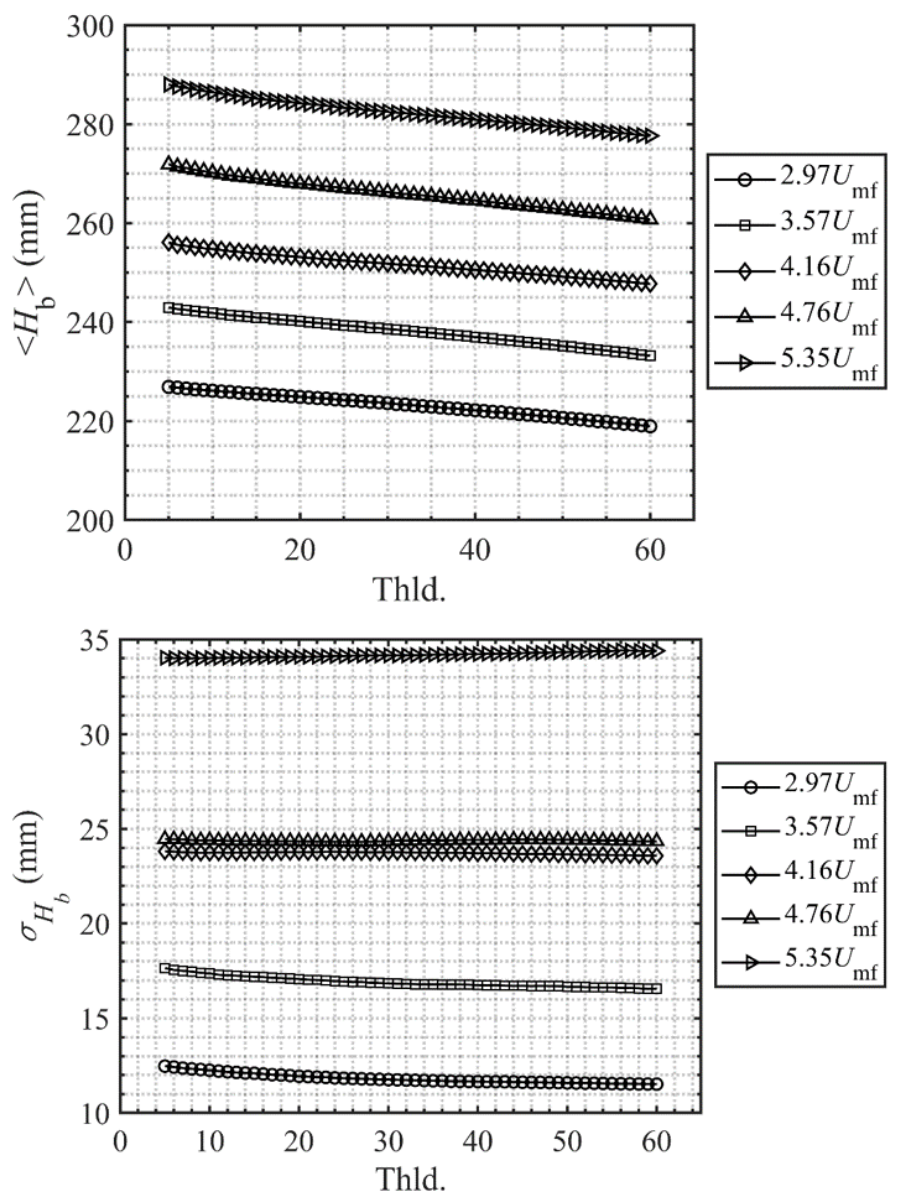

Figure 8: Mean (top) and Standard deviation (bottom) of bed height in 2.5-inch column. Abscissa refers to threshold value or percentage of pixels occupied by solids in a given frame. 

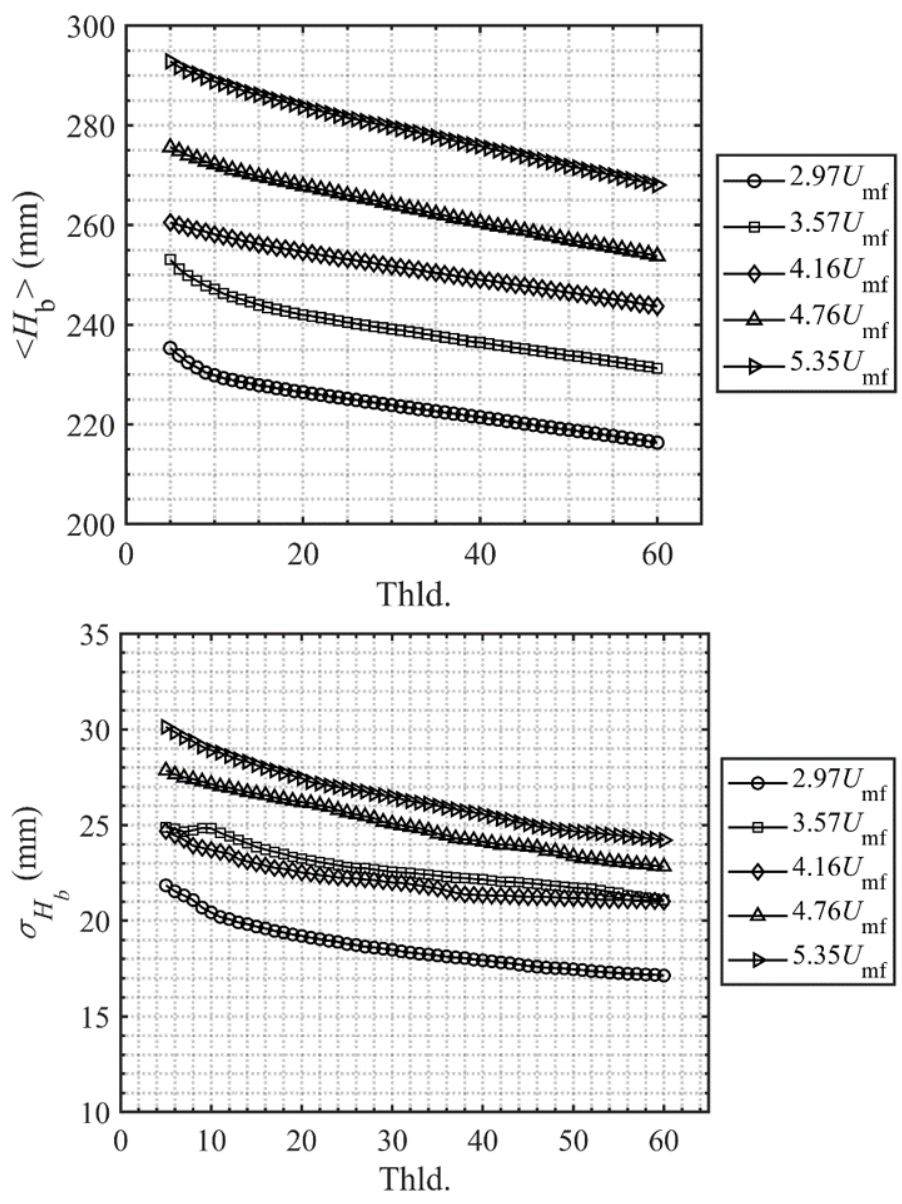

Figure 9: Mean (top) and Standard deviation (bottom) of bed height in 4-inch column. Abscissa refers to threshold value or percentage of pixels occupied by solids in a given frame. 

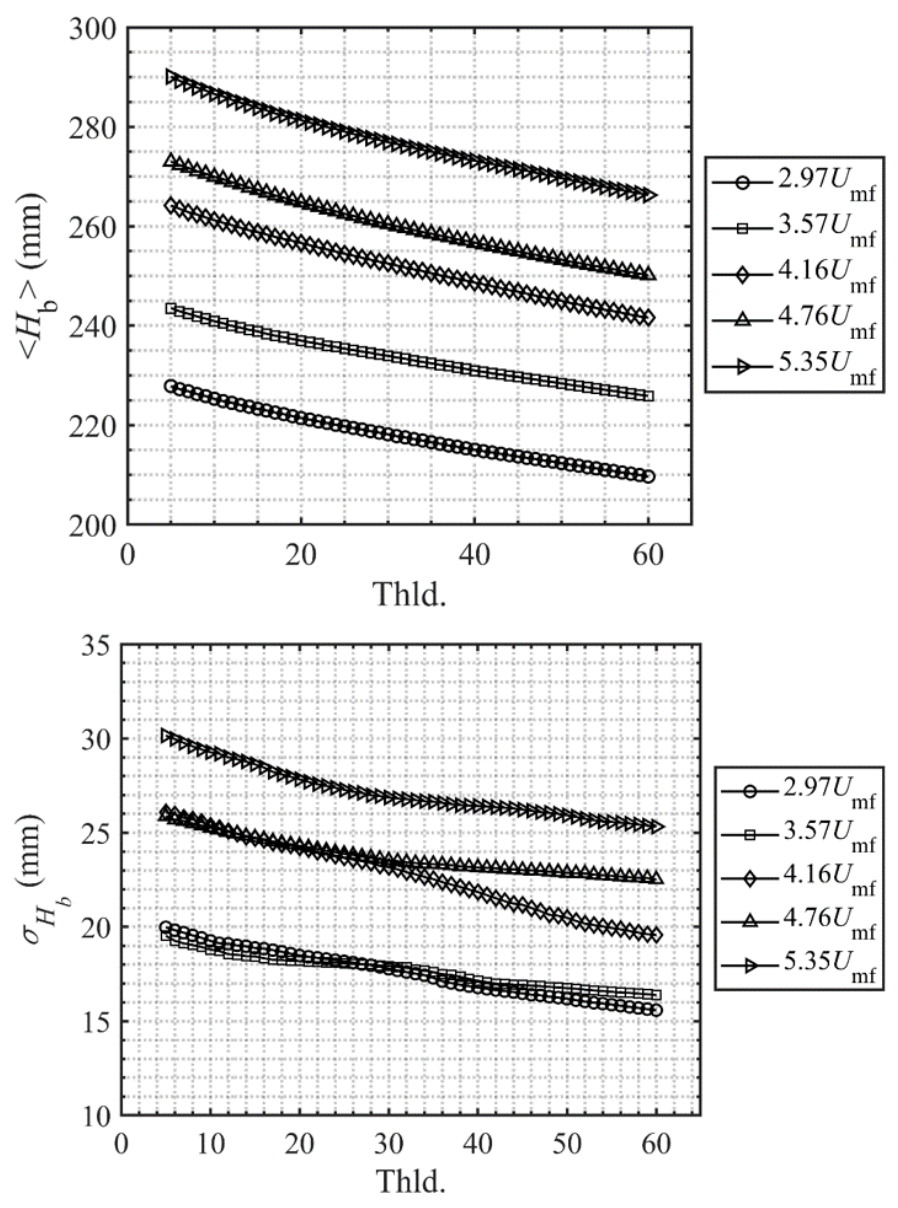

Figure 10: Mean (top) and Standard deviation (bottom) of bed height in 6-inch column. Abscissa refers to threshold value or percentage of pixels occupied by solids in a given frame. 


\section{Acknowledgement}

This work was performed in support of the US Department of Energy's Fossil Energy Crosscutting Technology Research. The work was executed through the NETL Research and Innovation Center's Advanced Reactor Systems Program. Research performed by Leidos Research Support Team staff was conducted under the RSS contract 89243318CFE000003.

\section{Disclaimer}

This work was funded by the Department of Energy, National Energy Technology Laboratory, an agency of the United States Government, through a support contract with Leidos Research Support Team (LRST). Neither the United States Government nor any agency thereof, nor any of their employees, nor LRST, nor any of their employees, makes any warranty, expressed or implied, or assumes any legal liability or responsibility for the accuracy, completeness, or usefulness of any information, apparatus, product, or process disclosed, or represents that its use would not infringe privately owned rights. Reference herein to any specific commercial product, process, or service by trade name, trademark, manufacturer, or otherwise, does not necessarily constitute or imply its endorsement, recommendation, or favoring by the United States Government or any agency thereof. The views and opinions of authors expressed herein do not necessarily state or reflect those of the United States Government or any agency thereof.

\section{References}

(1) Choi, K.-Y.; Ray, W. The dynamic behaviour of fluidized bed reactors for solid catalysed gas phase olefin polymerization. Chemical Engineering Science 1985, 40, 2261 - 2279.

(2) Kunii, D.; Levenspiel, O. Fluidization engineering; Butterworth-Heinemann, 1991. 
(3) Arbel, A.; Huang, Z.; Rinard, I. H.; Shinnar, R.; Sapre, A. V. Dynamic and Control of Fluidized Catalytic Crackers. 1. Modeling of the Current Generation of FCC's. Industrial \& Engineering Chemistry Research 1995, 34, 1228-1243.

(4) Abanades, J. C.; Anthony, E. J.; Wang, J.; Oakey, J. E. Fluidized Bed Combustion Systems Integrating CO2 Capture with CaO. Environmental Science $\mathcal{G}$ Technology 2005, 39, 2861-2866, PMID: 15884387.

(5) Salatino, P.; Solimene, R. Mixing and segregation in fluidized bed thermochemical conversion of biomass. Powder Technology 2017, 316, 29 - 40, Fluidization for Emerging Green Technologies.

(6) The behavior of biomass and char particles in a dual fluidized bed gasification system. Powder Technology 2018, 338, 887 - 897.

(7) Glicksman, L. R. Scaling relationships for fluidized beds. Chemical Engineering Science 1984, 39, $1373-1379$.

(8) Horio, M.; Nonaka, A.; Sawa, Y.; Muchi, I. A new similarity rule for fluidized bed scale-up. AIChE Journal 1986, 32, 1466-1482.

(9) Deterministic chaos: a new tool in fluidized bed design and operation. The Chemical Engineering Journal and the Biochemical Engineering Journal 1993, 53, 75 - 87.

(10) Schouten, J.; van der Stappen, M.; van den bleek, C. Scale-up of chaotic fluidized bed hydrodynamics. Chemical Engineering Science 1996, 51, 1991 - 2000, Chemical Reaction Engineering: From Fundamentals to Commercial Plants and Products.

(11) Briongos, J. V.; Guardiola, J. New methodology for scaling hydrodynamic data from a 2D-fluidized bed. Chemical Engineering Science 2005, 60, 5151 - 5163.

(12) Matsen, J. M. Scale-up of fluidized bed processes: Principle and practice. Powder Technology 1996, 88, 237 - 244, First International Particle Technology Forum. 
(13) Frye, C. G.; Lake, W. C.; Eckstrom, H. C. Gas-solid contacting with ozone decomposition reaction. AIChE Journal 1958, 4, 403-408.

(14) Stein, M.; Ding, Y.; Seville, J.; Parker, D. Solids motion in bubbling gas fluidised beds. Chemical Engineering Science 2000, 55, 5291 - 5300.

(15) Du, B.; Warsito, W.; Fan, L.-S. ECT Studies of GasSolid Fluidized Beds of Different Diameters. Industrial \&6 Engineering Chemistry Research 2005, 44, 5020-5030.

(16) Wu, B.; Yu, G.; Bellehumeur, C.; Kantzas, A. Dynamic Flow Behavior Measurements in Gas-Solid Fluidized Beds Using Different Non-Intrusive Techniques and Polyethylene Powder. Flow Measurement and Instrumentation 2007, 18, 197-203.

(17) Efhaima, A.; Al-Dahhan, M. H. Bed diameter effect on the hydrodynamics of gas-solid fluidized beds via radioactive particle tracking (RPT) technique. The Canadian Journal of Chemical Engineering 2017, 95, 744-756.

(18) Vaidheeswaran, A.; Shaffer, F.; Gopalan, B. Statistics of velocity fluctuations of Geldart A particles in a circulating fluidized bed riser. Phys. Rev. Fluids 2017, 2, 112301.

(19) Gel, A.; Vaidheeswaran, A.; Musser, J.; Tong, C. H. Toward the Development of a Verification, Validation, and Uncertainty Quantification Framework for Granular and Multiphase Flows - Part 1: Screening Study and Sensitivity Analysis . Journal of Verification, Validation and Uncertainty Quantification 2018, 3, 031001.

(20) Higham, J. E.; Shahnam, M.; Vaidheeswaran, A. On the Dynamics of a Quasi-TwoDimensional Pulsed-Fludized Bed. 2018.

(21) PTC, A. C. 602008 ANSI Standard V\&6 20 Guide for Verification and Validation in Computational Fluid Dynamics and Heat Transfer ; Standard, 2009.

(22) Wu, K.; de Martín, L.; Mazzei, L.; Coppens, M.-O. Pattern formation in fluidized beds 
as a tool for model validation: A two-fluid model based study. Powder Technology 2016, $295,35-42$.

(23) Snider, D. An Incompressible Three-Dimensional Multiphase Particle-in-Cell Model for Dense Particle Flows. Journal of Computational Physics 2001, 170, 523 - 549.

(24) Geldart, D. Types of gas fluidization. Powder Technology 1973, 7, $285-292$.

(25) Vaidheeswaran, A.; Pandey, R.; Clarke, M.; Ashfaq, H.; Rogers, W. Fluidization of Group A Glass Particles: Experiments and Preliminary Validation; Technical Report Series, National Energy Technology Laboratory, 2020.

(26) Cranfield, R.; Geldart, D. Large particle fluidisation. Chemical Engineering Science 1974, 29, $935-947$.

(27) Eisfeld, B.; Schnitzlein, K. The influence of confining walls on the pressure drop in packed beds. Chemical Engineering Science 2001, 56, 4321 - 4329.

(28) Delebarre, A. Does the Minimum Fluidization Exist? Journal of Fluids Engineering 2002, 124, 595-600.

(29) Felice, R. D.; Gibilaro, L. Wall effects for the pressure drop in fixed beds. Chemical Engineering Science 2004, 59, 3037 - 3040.

(30) Rao, A.; Curtis, J. S.; Hancock, B. C.; Wassgren, C. The effect of column diameter and bed height on minimum fluidization velocity. AIChE Journal 2010, 56, 2304-2311.

(31) Otsu, N. A Threshold Selection Method from Gray-Level Histograms. IEEE Transactions on Systems, Man, and Cybernetics 1979, 9, 62-66.

(32) Bi, H.; Ellis, N.; Abba, I.; Grace, J. A state-of-the-art review of gas-solid turbulent fluidization. Chemical Engineering Science 2000, 55, 4789 - 4825. 
(33) Schnitzlein, M. G.; Weinstein, H. Flow characterization in high-velocity fluidized beds using pressure fluctuations. Chemical Engineering Science 1988, 43, 2605 - 2614.

(34) Grace, J. R.; Sun, G. Influence of particle size distribution on the performance of fluidized bed reactors. The Canadian Journal of Chemical Engineering 1991, 69, 11261134.

(35) Sobrino, C.; Sánchez-Delgado, S.; García-Hernando, N.; de Vega, M. Standard deviation of absolute and differential pressure fluctuations in fluidized beds of group B particles. Chemical Engineering Research and Design 2008, 86, 1236 - 1242.

(36) Bi, X. Flow regime transitions in gas-solid fluidization and transport. Ph.D. thesis, 1994.

(37) Geldart, D. Expansion of Gas Fluidized Beds. Industrial \& Engineering Chemistry Research 2004, 43, 5802-5809.

(38) Guardiola, J.; Ramos, G.; Elvira, R. Measuring the height of a fluidized bed by computer vision. Chemical Engineering Science 2013, 95, 33 - 42.

(39) Penn, A.; Boyce, C. M.; Kovar, T.; Tsuji, T.; Pruessmann, K. P.; Müller, C. R. RealTime Magnetic Resonance Imaging of Bubble Behavior and Particle Velocity in Fluidized Beds. Industrial 85 Engineering Chemistry Research 2018, 57, 9674-9682. 